\title{
Evaluation of Hylife-II and Sombrero Using 175- and 566-Group Neutron Transport and Activation Cross Sections
}

\author{
J. F. Latkowski \\ D. E. Cullen \\ J. Sanz
}

This paper was prepared for submittal to the

5th International Symposium on Fusion Nuclear Technology

Rome, Italy

September 19-24, 1999

June 18, 1999

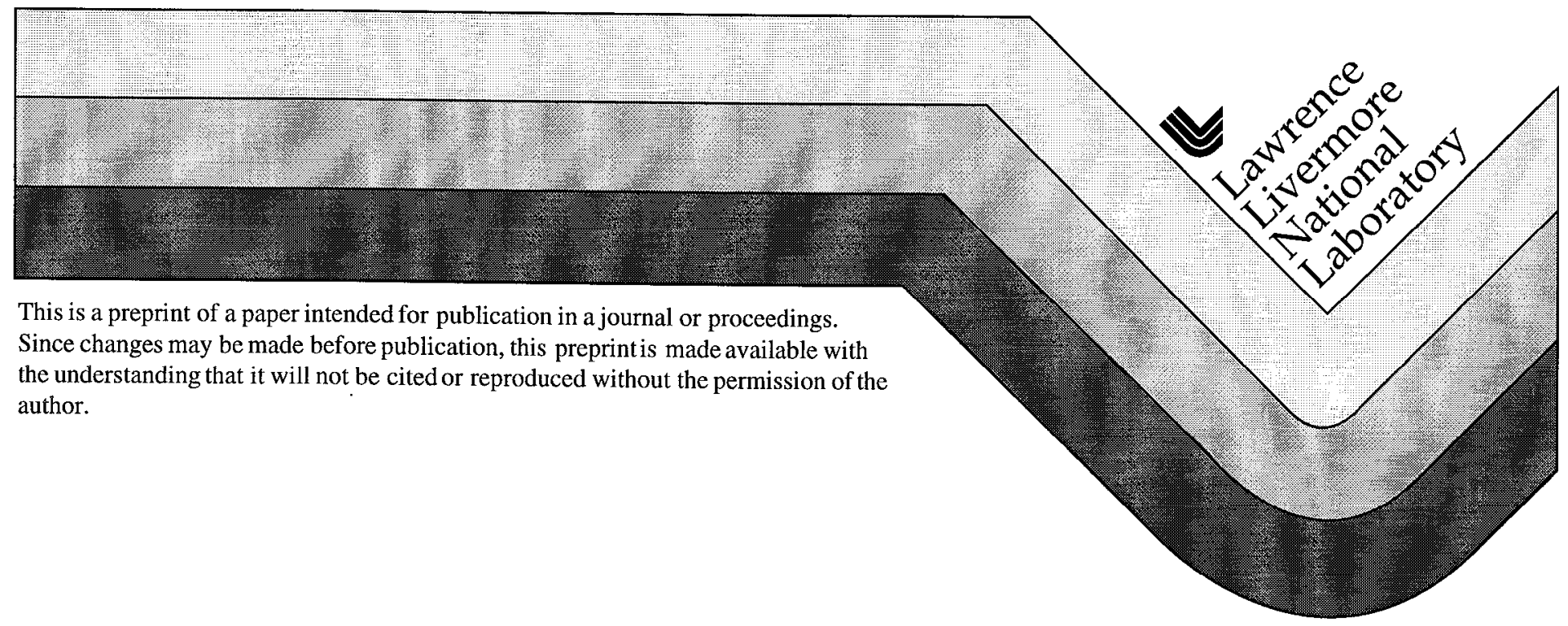




\section{DISCLAIMER}

This document was prepared as an account of work sponsored by an agency of the United States Government. Neither the United States Government nor the University of California nor any of their employees, makes any warranty, express or implied, or assumes any legal liability or responsibility for the accuracy, completeness, or usefulness of any information, apparatus, product, or process disclosed, or represents that its use would not infringe privately owned rights. Reference herein to any specific commercial product, process, or service by trade name, trademark, manufacturer, or otherwise, does not necessarily constitute or imply its endorsement, recommendation, or favoring by the United States Government or the University of California. The views and opinions of authors expressed herein do not necessarily state or reflect those of the United States Government or the University of California, and shall not be used for advertising or product endorsement purposes. 


\title{
EVALUATION OF HYLIFE-II AND SOMBRERO USING 175- AND 566-GROUP NEUTRON TRANSPORT AND ACTIVATION CROSS SECTIONS*
}

\author{
Jeffery F. Latkowski and Dermott E. Cullen \\ Lawrence Livermore National Laboratory \\ P. O. Box 808, Mailstop L-493 \\ Livermore, CA 94550 \\ 925-423-9378 \\ 925-423-4606 (FAX)
}

\author{
Javier Sanz \\ Universidad Nacional de Educacion a Distancia \\ Escuela Tecnica Superior Ingenieros \\ Industriales, Departamento Ingenieria Energetica \\ C/ Ciudad Universitaria, s/n, 28040 Madrid, \\ Spain \\ Also: Instituto Fusion Nuclear, Madrid
}

\begin{abstract}
Recent modifications to the TART Monte Carlo neutron and photon transport code allow enable calculation of 566-group neutron spectra. This expanded group structure represents a significant improvement over the 50- and 175-group structures that have been previously available. To support use of this new capability, neutron activation cross section libraries have been created in the 175- and 566-group structures starting from the FENDL/A-2.0 pointwise data. Neutron spectra have been calculated for the first walls of the HYLIFE-II and SOMBRERO inertial fusion energy power plant designs and have been used in subsequent neutron activation calculations. The results obtained using the two different group structures are compared to each other as well as to those obtained using a 175-group version of the EAF3.1 activation cross section library.
\end{abstract}

\section{Introduction}

In the present work, neutron spectra are presented for the first walls of the HYLIFE-II and SOMBRERO inertial fusion power plants using 175 and 566 groups $[1,2]$. These spectra have been calculated using an updated version of the TART98 Monte Carlo neutron and photon transport code [3]. This new version of TART has a minimum neutron energy of $10^{-10} \mathrm{MeV}$ and a maximum neutron energy of $1 \mathrm{GeV}$. The energies are divided logically into 650 groups with a standard distribution of 50 groups per decade. Although the code is capable of using the full, 650 groups, there is no data available above 20 $\mathrm{MeV}$. Thus, only 566 groups are of use in the current calculations. Neutron spectra have been calculated in the old 175-group structure and with the new, 566-group structure. 
A noteworthy benefit of the new group structure is an improvement in speed. Due to the logical division of energy groups, TART98 executes faster when the 566-group data is used instead of the 175group data. Evidently, when the 175-group data is used, TART spends a significant amount of CPU-time figuring out which energy group it is in following an interaction. By using the 566-group data, execution times are observed to fall by $10-20 \%$.

These neutron spectra are then used with 175- and 566-group versions of the FENDL/A-2.0 activation cross section library that have been created from the pointwise data [4]. The group constants were generated with the LINEAR and GROUPIE codes using a flat weighting spectrum across each energy group [5]. Using these libraries, radioactive inventories, occupational and routine hazards, and waste management hazards have been calculated for the two power plants. Activation calculations have been performed using the ACAB98 radionuclide generation/depletion code [6]. Differences between the 175and 566-group results are discussed, and recommendations are given for future assessments. The results are also compared with those obtained using a 175-group version of the EAF3.1 activation cross section library.

\section{Models and neutron spectra}

The objective of the present work is to establish whether or not a greater number of energy groups should be utilized in future transport and activation calculations. Given this objective, the use of simple models is justified. One-dimensional, spherical models of HYLIFE-II and SOMBRERO have been used. The following sections summarize the physical layout that has been assumed in these 1-D calculations. In both cases, the target has been modeled as a sphere with a radius of $0.01 \mathrm{~cm}$ and a $\rho \mathrm{of} 3 \mathrm{~g} / \mathrm{cm}^{2} . \Lambda 50-50$ mixture of deuterium and tritium has been assumed.

\subsection{HYLIFE-II model}

The HYLIFE-II power plant design features a thick-liquid blanket made of the molten-salt Flibe. The molar ratio of $\mathrm{LiF}$ to $\mathrm{BeF}_{2}$ is $2: 1$. Table 1 summarizes the HYLIFE-II geometry that has been modeled for the present work. Figure 1 shows the first wall lifetime for type 304 stainless steel (SS304) as a function of Flibe thickness. A damage limit of $100 \mathrm{dpa}$ is assumed. By using an effective thickness of $60 \mathrm{~cm}$ of Flibe 
between the target and structural components, the lifetime of SS304 is estimated to be 30 full-power years. Since one of the main goals of the HYLIFE-II design is to allow the first wall to last for the lifetime of the power plant, a $60 \mathrm{~cm}$ Flibe thickness is used. The $\$ S 304$ composition given in Reference 7 is assumed for activation calculations.

Using the model that has been described, neutron spectra are presented for HYLIFE-II in 175- and 566-group energy structures. Figure 2 shows both sets of spectra. Due to the large thermal neutron absorption cross section in Flibe, few neutrons below $\sim 10^{-6} \mathrm{MeV}$ make it to the SS304 first wall. As the figure shows, the calculated neutron spectra match quite well. This is a good benchmark of the new capability and data in the new group structure. At neutron energies of $2 \times 10^{-7}$ to $2 \times 10^{-6} \mathrm{MeV}$, there is considerable uncertainty in the fluxes. This is due, in part, to poor statistics at such low energies. Running a very large number of particles would rectify the situation or, preferably, TART could be modified to allow particle splitting at boundaries according to ranges of neutron energies. Currently, TART allows particle splitting, but the user cannot select only a portion of the neutron spectrum to be split.

\subsection{SOMBRERO model}

Rather than using a thick-liquid protection scheme in front of the first structural wall, the SOMBRERO power plant design makes use of low-activation carbon composites. Table 2 summarizes the 1-D, spherical model that has been used. Previous work has suggested that a damage limit of 75 dpa may be attainable in carbon/carbon $(\mathrm{C} / \mathrm{C})$ composites [2]. This would allow a 5 full-power year lifetime for the SOMBRERO first wall. The present work assumes a 5 year lifetime and, consequently, activation calculations assume 5 years of irradiation. Activation calculations have assumed the $\mathrm{C} / \mathrm{C}$ composite composition given in Reference 2 .

Figure 3 shows the neutron spectra as calculated for the SOMBRERO first wall using 175- and 566group cross sections. As in the HYLIFE-II calculations, little difference is seen among the results. Since SOMBRERO does not utilize a thick-liquid protection scheme, neutrons as low as $10^{-9} \mathrm{MeV}$ are observed in the first wall. The flux also peaks at a value close to $10^{17} \mathrm{n} / \mathrm{cm}^{2}-\mathrm{s}-\mathrm{MeV}$, while it only reaches $\sim 10^{12}$ $\mathrm{n} / \mathrm{cm}^{2}$-s-MeV in the HYLIFE-II first wall. While the 175-group energy structure only has 6 energy groups 
betwecn $10^{-9}$ and $10^{-7} \mathrm{MeV}$, the new group structure has 100 groups. Although once again there is considerable scatter in the low-energy fluxes, the 566-group results appear to follow the 175-group results.

\section{Results}

Given that the first wall neutron spectra look quite similar for 175- and 566-group calculations in both HYLIFE-II and SOMBRERO, the only differences in activation results that might be expected are for (1) high-energy threshold reactions where the reaction rate is non-zero in only a few energy groups, or (2) lowenergy reactions where the true shape of the neutron spectrum requires the detail available in the 566-group structure. Both cases are truly manifestations of the same effect - the flux is changing rapidly within an energy group.

\subsection{HYLIFE-II results}

The first wall activation calculation has been performed using the 175- and 566-group neutron fluxes. A comparison of each radionuclide's activity at 1 minute after shutdown was made, and 34 radionuclides were found to differ by at least $10 \%$. The half-lives of these radionuclides range from $<1 \mathrm{~s}$ to $730,000 \mathrm{y}$. None of the radionuclides, however, comprise a significant portion of the total activity in the SS304 first wall. In order to ensure that these radionuclides are unimportant for accident doses one would still need to perform detailed accident analyses including time-temperature histories and radionuclide mobilization.

Although the total waste disposal rating (WDR) is nearly identical using the two group structures, it is interesting to note that the contribution from ${ }^{26} \mathrm{Al}\left(\sim 5 \times 10^{-3}\right)$ is about $38 \%$ for the 566 -group result. ${ }^{26} \mathrm{Al}$ is produced entirely via the ${ }^{27} \mathrm{Al}(\mathrm{n}, 2 \mathrm{n})$ reaction, which has a threshold of $13.54 \mathrm{MeV}$. The difference between the calculated inventories stems from the fact that the reaction rate changes rapidly within the threshold energy groups. In the 175-group calculation, two energy groups make contributions to the total reaction rate (group energies are 13.54-13.86 MeV and 13.86-14.13 MeV). In the 566-group calculation, again, two groups make a contribution. This time, however, the reaction threshold energy lies in the middle of the lower energy group $(E=13.18-13.80 \mathrm{MeV})$. This produces a difference in the group-averaged reaction rate, and thus, a difference in the total inventory. 
A comparison of the contact dose rates calculated using 175- and 566-group fluxes and cross sections shows effects similar to those obscrved in the WDR calculations. The total contact dose rates are nearly identical, but ${ }^{22} \mathrm{Na}$ and ${ }^{26} \mathrm{Al}$ contributions both differ by $\sim 38 \%$. ${ }^{22} \mathrm{Na}$ is produced largely via the ${ }^{23} \mathrm{Na}(\mathrm{n}, 2 \mathrm{n})$ reaction, which has a threshold of $12.96 \mathrm{MeV}$, and an effect similar to that described above for ${ }^{26} \mathrm{Al}$ occurs.

\subsection{SOMBRERO results}

Activation calculations for the SOMBRERO first wall show effects that are similar to those observed in the HYLIFE-II cases. A sizable number of radionuclide inventories differ significantly, but most of these probably would not be significant contributors to the accident doses. Forty-seven radionuclide inventories differ by at least $10 \%$ when calculated with the 175- and 566-group energy structures. Radionuclides that may potentially be important for accident doses include ${ }^{18} \mathrm{~F},{ }^{22} \mathrm{Na},{ }^{30} \mathrm{P},{ }^{35} \mathrm{~S}$, and ${ }^{45} \mathrm{Ti}$.

A comparison of the first wall activities calculated with EAF3.1 to those calculated with the 175-group version of FENDL/A-2.0 shows considerable differences. A total of 127 radionuclides differ by at least $10 \%$ and 25 differ by at least an order of magnitude. This confirms findings reported in previous work such as that by Sanz et al. [8].

WDR results show good agreement between the 175 - and 566 -group calculations. Only ${ }^{26} \mathrm{Al}$ and ${ }^{44} \mathrm{Ti}$ show more than a few percent difference, and these isotopes do not make significant contributions to the total WDR. Comparison with EAF3.1 results, however, shows significant differences in the ${ }^{14} \mathrm{C}$ and ${ }^{26} \mathrm{Al}$ values. Since these isotopes dominate the total WDR, significant differences are observed. The total WDR is $3 \times$ lower for the EAF3.1 case than calculated using FENDL.

Contact dose rates agree quite well at early times, but significant differences are observed at cooling times of 1 ycar and beyond. Both results suggest that a remote recycling limit of $10 \mathrm{mSv} / \mathrm{hr}$ can be met after only $\sim 7$ years. Differences in the calculated ${ }^{22} \mathrm{Na}$ inventory, which dominates the contact dose rate from cooling times of several months to $\sim 50$ years, inject an uncertainty of $\sim 1$ year in the time at which the hands-on recycling limit is reached. Contact dose rate results using the E.AF3.1 library would suggest that the hands-on recycling limit could be reached after only $\sim 15$ years of cooling. This large difference arises from the fact that EAF3.1 underestimates the ${ }^{22} \mathrm{Na}$ production by nearly 2 orders of magnitude. 


\section{Conclusions and recommendations}

Ncutron transport and activation calculations have bcen completed using ENDL 175- and 566-group neutron transport cross sections and activation cross sections created from the FENDL/A-2.0 pointwise activation data. Largely, these calculations have shown that the radionuclide inventories calculated with either group structure agree quite well. Radionuclides produced via high-energy threshold reactions $\left(E_{n}>\right.$ $10 \mathrm{MeV}$ ) appear to suffer from effects caused by the particular group structure. While the total activities, waste disposal ratings, and contact dose rates for the HYLIFE-II and SOMBRERO first walls have not been significantly affected, one should carefully consider the group structure that is used if such radionuclides are important.

\section{Acknowledgments}

Work performed under the auspices of the U. S. Department of Energy by Lawrence Livermore National Laboratory under Contract W-7405-Eng-48, and Ministerio de Educación y Cultura, Spain, under Project DGCIT PB95-0230. 
Table 1

A one-dimensional model of HYI,IFE-II

\begin{tabular}{lll}
\hline Component & Inner/outer radii $(\mathrm{cm})$ & Material composition \\
\hline Flibe pocket & $30 / 90$ & full-density Flibe \\
First wall & $300 / 300.3$ & SS304 \\
Blanket coolant & $300.3175 / 350.3$ & full-density Flibe \\
Blanket structure \#1/3 & $350.3 / 352.54$ & SS304 \\
Blanket coolant & $352.54 / 355.08$ & full-density Flibe \\
Blanket structure \#2/3 & $355.08 / 357.62$ & SS304 \\
Insulation with purge gas & $357.62 / 367.78$ & void \\
Blanket structure \#3/3 & $367.78 / 367.94$ & SS304 \\
\hline
\end{tabular}


Table 2

A one-dimensional model of SOMBRERO

\begin{tabular}{lll}
\hline Component & Inner/outer radii $(\mathrm{cm})$ & Material composition \\
\hline Chamber gas & $0 / 650$ & 0.5 Torr of xenon \\
First wall & $650 / 651$ & $\mathrm{C} / \mathrm{C}$ composite \\
Blanket \#1/3 & $651 / 670$ & $97 \mathrm{v} \% \mathrm{Li}_{2} \mathrm{O}(60 \%$ packing fraction $)$ \\
& & $+3 \mathrm{v} \% \mathrm{C} / \mathrm{C}$ composite \\
Blanket \#2/3 & $670 / 710$ & $80 \mathrm{v} \% \mathrm{Li}_{2} \mathrm{O}(60 \%$ packing fraction) \\
& & $+20 \mathrm{v} \% \mathrm{C} / \mathrm{C}$ composite \\
Blanket \#3/3 & $50 \mathrm{v} \% \mathrm{Li}_{2} \mathrm{O}(60 \%$ packing fraction $)$ \\
& $710 / 750$ & $+50 \mathrm{v} \% \mathrm{C} / \mathrm{C}$ composite \\
\hline
\end{tabular}




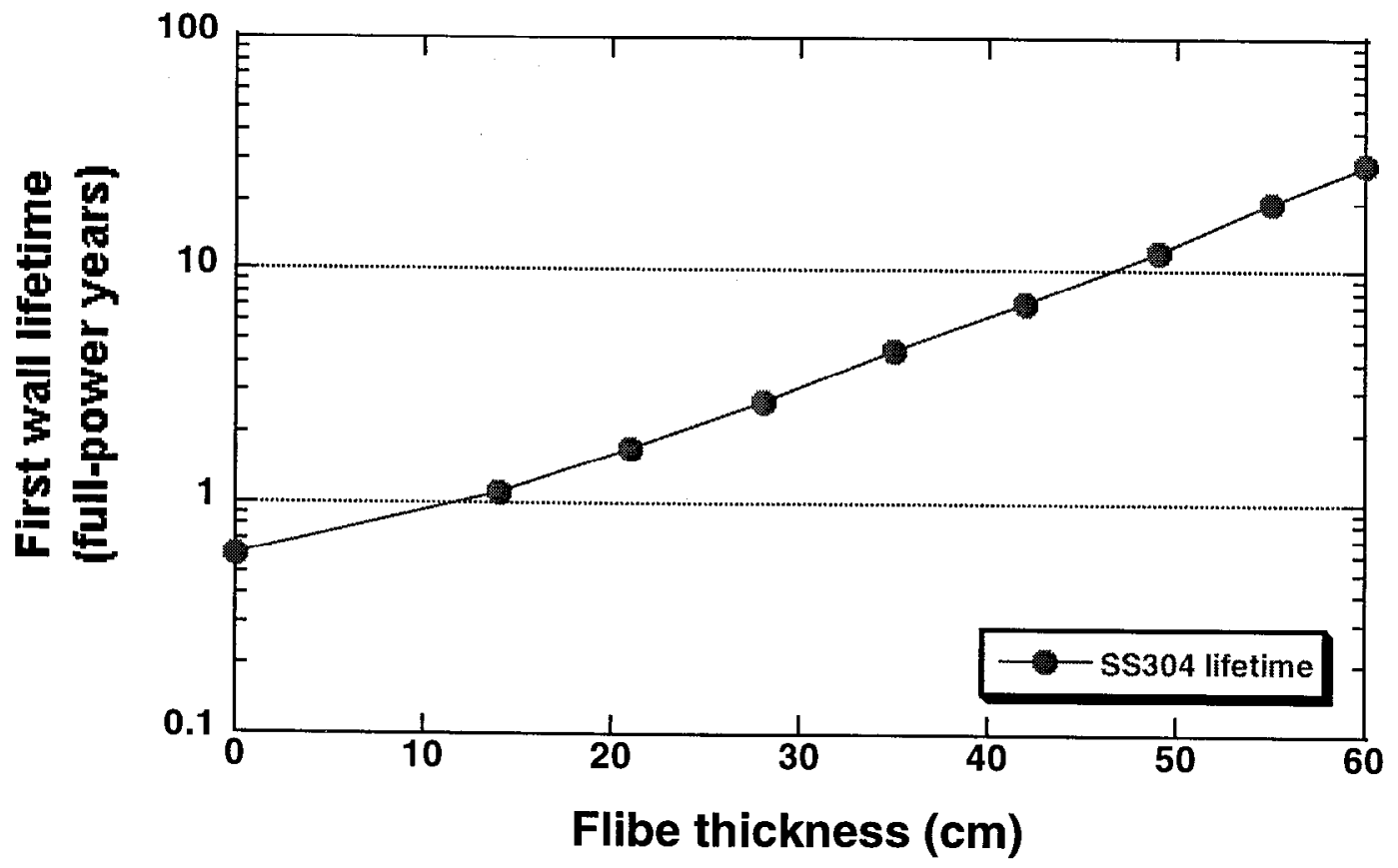

Figure 1 


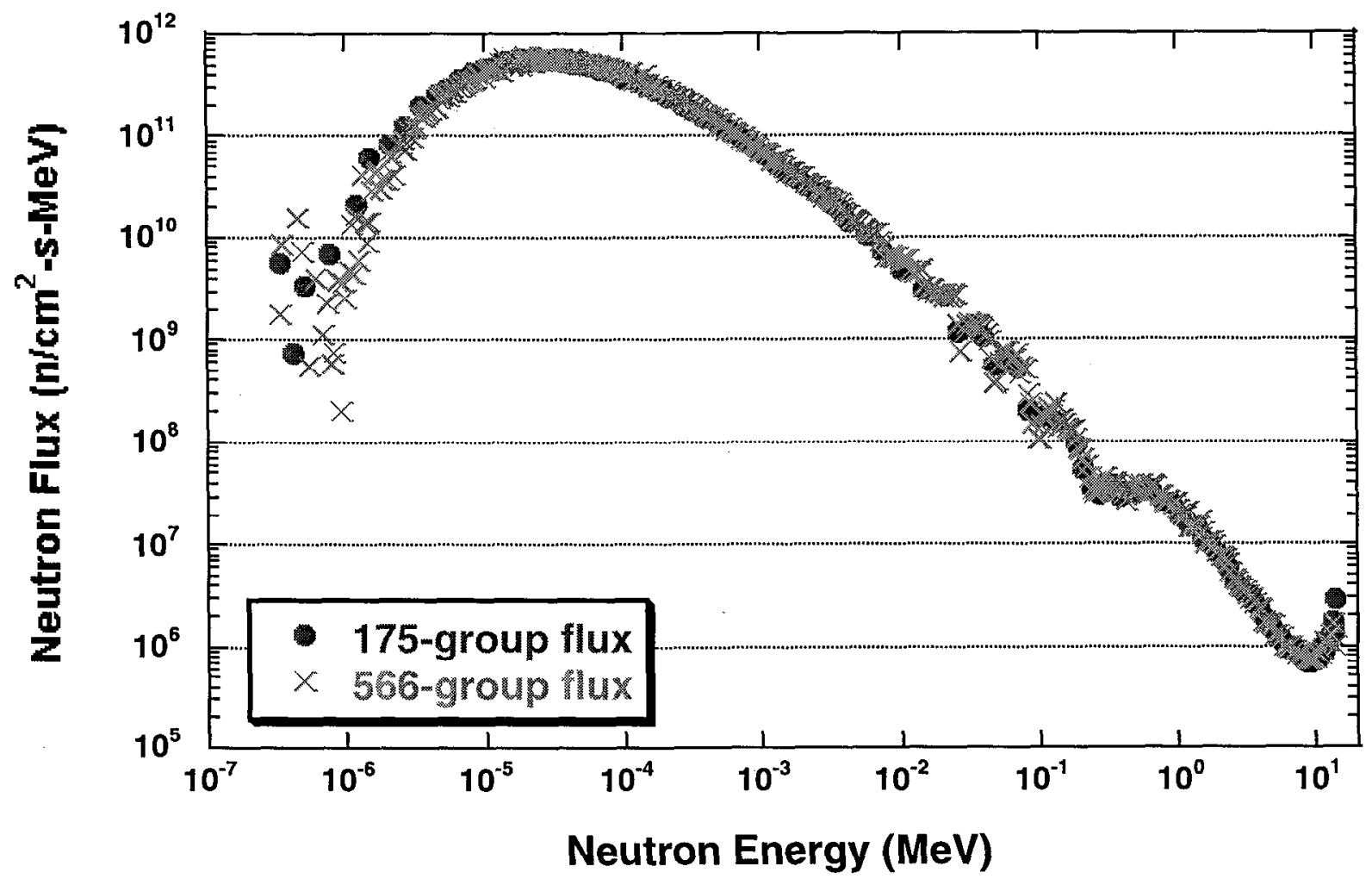

Figure 2 


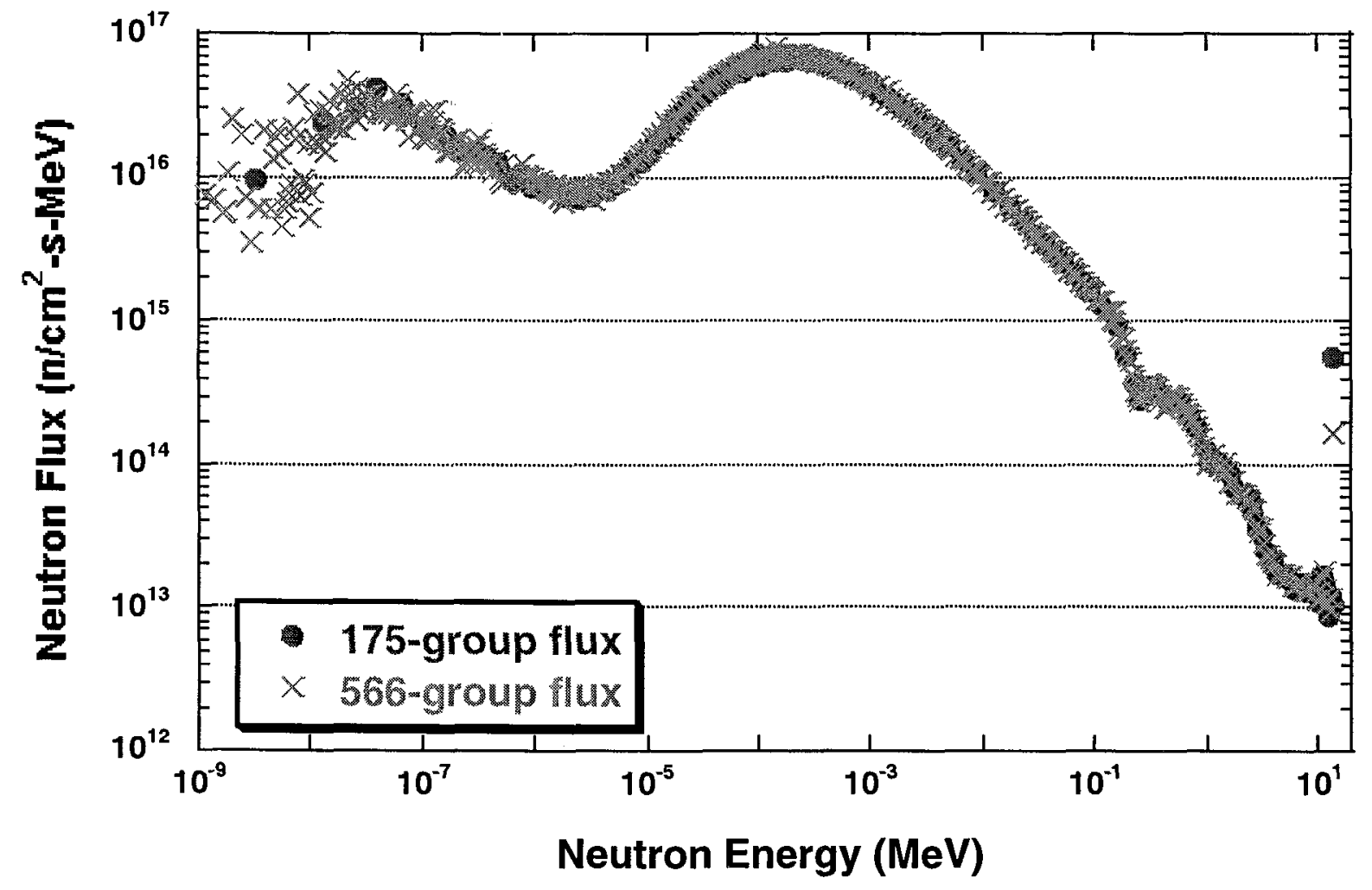

Figure 3 
Fig. 1. Lifetime of HYLIFE-II first wall as function of Flibe thickness.

Fig. 2. Neutron spectrum in the HYLIFE-II first wall.

Fig. 3. Neutron spectrum in the SOMBRERO first wall. 


\section{References}

[1] R. W. Moir, R. L. Bieri, X. M. Chen, T. J. Dolan, M. A. Hoffman, P. A. House, R. L. Leber, J. D. Lee, Y. T. Lee, J. C. Liu, G. R. I conghurst, W. R. Meier, P. F. Peterson, R. W. Petzoldt, V. E. Schrock, M T. Tobin and W. H. Williams, HYLIFE-II - a molten-salt inertial fusion energy power plant design - final report, Fus. Technol. 24 (1994) 5-25.

[2] W. R. Meier, R. L. Bieri, M. J. Monsler, C. D. Hendricks, P. Laybourne, K. R. Shillito, S. K. Ghose, L. M. Goldman, K. D. Auclair, C. Y. Pang, R. F. Bourque, L. D. Stewart, E. E. Bowles, E. L. Hubbard, C. W. von Rosenberg, Jr., M. W. McGeoch, I. N. Sviatoslavsky, R. R. Peterson, M. E. Sawan, H. Y. Khater, L. J. Wittenberg, G. L. Kulcinski, G. A. Moses, E. A. Mogahed, J. J. MacFarlane, S. Rutledge, S. Humphries, Jr. and E. T. Cheng, Osiris and SOMBRERO inertial confinement fusion power plant designs, W. J. Schafer Associates, Inc., DOE/ER/54100-1, WJSA-92-01, March 1992.

[3] D. E. Cullen, TART98: a coupled neutron photon, 3-D, combinatorial geometry, time dependent, Monte Carlo transport code, Lawrence Livermore National Laboratory, UCRL-ID-126455, Rev. 2, November 1998.

[4] A.B Pashchenko, H. Wienke, J. Kopecky, J.-CH Sublet and R.A. Forrest, FENDL/A-2.0 neutron activation cross-section data library for fusion applications, International Atomic Energy Agency, IAEANDS-173, March 1997.

[5] D. E. Cullen, The 1996 ENDF pre-processing codes, International Atomic Energy Agency, IAEANDS-39, Rev. 9, November 1996.

[6] J. Sanz, ACAB98: Activation code for fusion applications. User's manual V4.0, Universidad Nacional de Educacion a Distancia, Lawrence Livermore National Laboratory, UCRL-CR-133040, February 1999. 
[7] J. D. Lee, Waste disposal assessment of HYLIFE II structure, Fus. Technol. 26 (Aug. 1994) 74-78.

[8] J. Sanz, C. González and J. Juan, Long-lived activity of elements: effect of new activation crosssections and their uncertainties on the selection of materials for IFE reactors, J. Nucl. Mat. 258-263 (1998) 1700-1707. 